\title{
Tinnitus in Elderly Individuals: Discomfort and Impact in the Quality of Life
}

\author{
Adriane Ribeiro Teixeira ${ }^{1}$ Leticia Petersen Schmidt Rosito ${ }^{2}$ Andréa Kruger Gonçalves ${ }^{3}$ \\ Michelle Gassen Paulo Nunes ${ }^{4}$ Silvia Dornelles ${ }^{1}$ Maira Rozenfeld Olchik ${ }^{5}$ \\ ${ }^{1}$ Department of Health and Human Communication, Universidade \\ Federal do Rio Grande do Sul, Porto Alegre, RS, Brazil \\ ${ }^{2}$ Department of Otolaryngology - Head and Neck Surgery, Hospital de \\ Clínicas de Porto Alegre, Porto Alegre, RS, Brazil \\ ${ }^{3}$ Departamento de Educação Física, Universidade Federal do Rio \\ Grande do Sul, Porto Alegre, RS, Brazil \\ ${ }^{4}$ Arqué Segurança e Medicina do Trabalho, Porto Alegre, RS, Brazil \\ ${ }^{5}$ Departamento de Cirurgia e Ortopedia, UFRGS, Porto Alegre, Rio RS \\ Brazil \\ Int Arch Otorhinolaryngol 2017;21:66-71. \\ Address for correspondence Adriane Ribeiro Teixeira, MD, PhD, \\ Department of Health and Human Communication, Universidade \\ Federal do Rio Grande do Sul, Porto Alegre, Rio Grande do Sul, Brazil \\ (e-mail: adriane.teixeira@gmail.com).
}

\begin{abstract}
Keywords

- tinnitus

- elderly

- quality of life

- questionnaires

Introduction Tinnitus is a symptom that affects mainly the elderly and can negatively influence their quality of life.

Objective The objective of our study is to evaluate the existence of a relationship between the quality of life and the impact caused by tinnitus in elderly individuals, considering the age and gender variables.

Method We conducted a cross-sectional study in elderly people of both genders who participate in the extension activities at the university. The evaluation was composed of anamnesis and WHOQOL-OLD instruments, to evaluate the quality of life, and Tinnitus Handicap Inventory (THI) for the evaluation of the tinnitus impact.

Result We evaluated 36 elderly individuals with an average age of $68.6 \pm 6.8$ years old, $72.2 \%$ of them were women. We verified that most of the subjects classified their tinnitus as weak (44.4\%) or medium (36.1\%). The score average in the THI was 20 points, with predominant classification of tinnitus impact as negligible (41.7\%) or mild (30.6\%). In the WHOQOL-OLD, the average score was $15.6 \pm 1.6$ points (total score). The negative correlation between the THI score and the WHOQOL-OLD score was found in the sensory domain operation and total score.

Conclusion The results obtained in the study prove that the quality of life of the elderly individuals evaluated is related to a discomfort caused by the tinnitus.
\end{abstract}

\section{Introduction}

Tinnitus is a frequent symptom in individuals of several age groups. Age increase, however, is one of the factors that determine its presence, ${ }^{1}$ and it is more common among the individuals from 40 years old on. ${ }^{2}$ A study reveals that there may be a relation between the presence of tinnitus and the hearing loss presented by the elderly. ${ }^{3}$

received

October 31, 2015

accepted

December 2, 2015

published online

April 13, 2016
The prevalence among elderly individuals is variably described in the consulted literature. A Japanese study reported the presence of tinnitus in $11.9 \%$ of middle-aged adults and elderly people. A population survey performed in the United States showed that tinnitus was present in $14.4 \%$ of the middle-aged adults and elderly individuals. ${ }^{4}$ The influence of the gender variable on the presence of tinnitus is still controversial in the specialized literature.

Copyright $\odot 2017$ by Thieme-Revinter

Publicações Ltda, Rio de Janeiro, Brazil
License terms

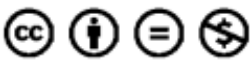


While some national and international studies state that gender does not influence tinnitus, ${ }^{5,6}$ others highlight that it is more frequent in women ${ }^{1}$ or in men. ${ }^{4,7}$

Some research states that the tinnitus can cause stress and emotional alterations, interfering in the quality of life and even preventing individuals from having a life considered normal. ${ }^{2,7,8}$ Other studies, however, highlight that the impact of the tinnitus in the quality of life is highly variable. While some individuals say that the symptom does not cause any trouble in their daily activities, others say they are highly harmed. ${ }^{5,9}$ Thus, it is difficult to initially determine whether tinnitus will or will not have a negative impact in the quality of life. The presence of depression, anxiety, neuroticism, psychasthenia, and schizoid aspects may be indicators that the tinnitus impact will be higher, ${ }^{10,11}$ but there is still not enough scientific evidence that the use of antidepressants promotes improvement in tinnitus. $^{12}$

The evaluation of tinnitus impact can be done in several ways. One of the most used instruments worldwide is the Tinnitus Handicap Inventory (THI), developed by Newman, Jacobson, and Spritzer. ${ }^{13}$ It has a version in Brazilian Portuguese. $^{14}$ The instrument is composed of 25 questions that evaluate how tinnitus interferes in daily activities.

Quality of life can be measured through different methods, from the use of wide and qualitative questions to the use of closed questionnaires, allowing us to quantify different aspects of the variable. Because it is a widely impacting and important topic, it has been studied for some time by the World Health Organization (WHO) researchers. Based on several studies and with researchers from several countries, quality of life is defined as "the individual's perception of their life position within the context of culture systems and values in which they are inserted and related to their objectives, expectations, standards, and concerns." 15 From this definition, the researchers elaborated questionnaires to evaluate quality of life, initially broad and comprehensive and further reduced and applicable to specific populations, as the WHOQOL-OLD (World Health Organization Quality of Life - Older Adults), to be used specifically with the elderly. ${ }^{16}$

The application and the joint analysis of these two instruments can be useful in clinical practice, evaluation processes, diagnosis, and treatment of elderly with tinnitus, enabling a broad view of the individual, not limited to the specific aspect of the tinnitus. A search in the literature, however, showed that it is rare to find papers in which instruments to evaluate the quality of life and to evaluate tinnitus are used together, 5,8 specially in Brazil, or instruments for the evaluation of quality of life developed specifically for the elderly.

Therefore, considering the lack of studies, the fact that Brazil has a significant and ever-increasing number of elderly individuals, and given the need to study the disorders presented by the population group with a focus on maintaining quality of life, we decided to carry out this study. Thus, the study aims to evaluate the relation between the quality of life and the impact caused by the tinnitus in elderly individuals, considering the age and gender variables.

\section{Method}

This is a study with a cross-sectional design. The sample was composed of elderly individuals of both genders, from 60 years old on, who had tinnitus. We selected the sample based on convenience. We considered all the seniors to be physically active because they would participate in extension projects in the institution, and they would practice physical exercises and other activities promoted by the projects (lectures and workshops).

The individuals included in the sample were elderly that reported tinnitus and were available to voluntarily participate in the research, signing a free and clarified consent term (TCLE), and filling out all questionnaires used for data collection. The individuals excluded were the ones with a history of psychiatric cognitive alterations.

Initially, we approached the elderly individuals at the university facilities and invited them to participate in the research. Those who accepted were led to a room where they signed the TCLE and were instructed on filling out of the questionnaires used in the research. Elderly with difficulties in reading and writing received help from a trained researcher previously, in order not to induce answers.

Initially, we carried out an anamnesis, aimed at obtaining sociodemographic data of the elderly. During the initial interview, the participants were questioned about their age, school level, marital status, and diseases. At this point, they were also invited to subjectively analyze the intensity of the tinnitus that they presented, classifying it as weak, medium, or strong. After that, everyone responded to the quality of life evaluation instrument of the World Health Organization, the WHOQOL-OLD, and the THI, to evaluate the impact of the tinnitus in their daily activities.

WHOQOL-OLD is an instrument developed by WHO, already translated and validated for Brazilian Portuguese, ${ }^{16}$ developed to be specifically applied to elderly individuals. The questionnaire is composed of 24 items that allow the evaluation of six parts or domains: operation of the sensory domain; past, present, and future activities; social participation; death and dying; and intimacy. It is also possible to evaluate the total score obtained in the instrument. For each one of the 24 questions, the individual must check one of the five alternatives presented. The higher the score obtained, the better the quality of life of the individual evaluated.

The impact of the tinnitus was evaluated by the THI instrument, also translated to and validated for Brazilian Portuguese. ${ }^{14}$ There are 25 questions that assess the influence of the tinnitus in daily situations. For each situation, the individual must check one of the three alternatives presented (yes -4 points; sometimes 2 points; no -0 points). The total score varies from 0 to 100 points (or \%), and the impact of the symptom can be considered negligible (0 to $16 \%$ ), mild (18 to $36 \%$ ), moderate (38 to $56 \%$ ), severe (58 to $76 \%$ ), or catastrophic ( 78 to $100 \%$ ). Therefore, the higher the score, the higher the negative impact of the tinnitus in the life of the individual evaluated.

The data were analyzed statistically and in a descriptive quantitative manner. With the help of the software SPSS (Statistical Package for the Social Sciences), version 17.0, 
absolute and relative frequencies were calculated for the categorical variables and for the central tendency measures (mean and median) and variability (standard deviation, range and interquartile range) for the continuous variables, where for the latter the symmetry of distributions was checked by the Kolmogorov-Smirnov test.

The bivariate analysis between categorical variables was done by the Pearson Chi-square test and Fisher's exact test. In the comparison of the continuous variables between two independent groups, we used the t-Student and the Mann Whitney test. When comparing three or more independent groups, we used the Variance Analysis (One Way) - Post Hoc Tukey - or Kruskal Wallys - Post Hoc Dunn test. To evaluate the linearity relation between the continuous variables, the Pearson or Spearman correlation coefficients were used. For statistical decision criteria, we adopted a level of significance adopted $(\alpha) 5 \%$.

The Ethics Research Committee of the institution evaluated and approved the study, under number 2008-125H.

\section{Results}

The sample consisted of 36 elderly individuals, mainly women (72.2\%). The age average was $68.6 \pm 6.8$ years. Considering the age groups, there was greater concentration in the group aged 60 to 69 years, $63.9 \%(n=23)$. Regarding school level, most individuals had gone to basic school (63.9\%), 38.9\% having not completed it and $25 \%$ having completed it. When instructed to subjectively classify the sensation of the tinnitus intensity, approximately half of the sample said it was weak (44.4\%). The characterization of the sample is found on - Table $\mathbf{1}$.

Regarding the score in the THI, this variable presented an asymmetric distribution, indicating that the estimates should occur as a function of the median and not of the mean. The median was 20 points.

As for the THI score classification, the largest part of the sample presented discomfort considered negligible and mild. The data are presented in - Table 2.

The analysis of the data between the THI score and the gender variable showed a significant difference $(\mathrm{p}<0.05)$, indicating that the scores for the men (median $=6.0$ points) were smaller than for the women (median $=22.0$ points) (-Table 3). When the THI score was compared with the age and to the age group, the significant differences were not confirmed, indicating that the THI score does not depend on the age of the individuals evaluated.

The evaluation data of the quality of life, evaluated through the WHOQOL-OLD, have shown that the elderly present average scores that vary according to the domain evaluated and are presented on - Table 4.

When the average of the domains was compared with each other, there were no significant differences $(\mathrm{p}>0.05)$, indicating that the domains presented similar average scores. Therefore, although the averages of the domains have presented variations, they were expressive to the point of affirming that the quality of life in a certain domain is better than in the other.

The comparative analysis that involved the WHOQOLOLD domain scores and the THI scores showed that there was a significant negative correlation of moderate degree
Table 1 Sample characterization

\begin{tabular}{|l|l|}
\hline Variables & $\mathbf{n}=36$ \\
\hline Gender $\mathbf{n} \mathbf{n}(\%)$ & \\
\hline Female & $26(72.2)$ \\
\hline Male & $10(27.8)$ \\
\hline Age (years) & \\
\hline Average \pm Standard Deviation & $68.6 \pm 6.8$ \\
\hline Minimum - Maximum & $60-83$ \\
\hline Age group (years) - $\mathbf{~ ( \% ) ~}$ & \\
\hline 60 to 69 & $23(63.9)$ \\
\hline 70 to 79 & $9(25.0)$ \\
\hline More than 79 & $4(11.1)$ \\
\hline Education & \\
\hline Never studied & $2(5.6)$ \\
\hline Incomplete primary education & $14(38.9)$ \\
\hline Primary education & $9(25.0)$ \\
\hline Incomplete high school & $1(2.8)$ \\
\hline High School & $6(16.7)$ \\
\hline Incomplete university & $2(5.6)$ \\
\hline University & $2(5.6)$ \\
\hline
\end{tabular}

Table 2 Absolute and relative distribution for the score and classification THI

\begin{tabular}{|l|l|}
\hline Variables & $\mathbf{n}=36$ \\
\hline Scores THI $€$ & \\
\hline Median $\left(\mathrm{Q}_{1}-\mathrm{Q}_{3}\right.$ quartile) & $20.0(6.0-41.0)$ \\
\hline Minimum - maximum & $0-96$ \\
\hline Classification $\mathrm{THI}-\mathbf{n}(\%)$ & \\
\hline Negligible $(0-16 \%)$ & $15(41.7)$ \\
\hline Mild (18-36\%) & $11(30.6)$ \\
\hline Moderate (38-56\%) & $7(19.4)$ \\
\hline Severe (58-76\%) & $1(2.8)$ \\
\hline Catastrophic (78-100\%) & $2(5.6)$ \\
\hline
\end{tabular}

Abbreviation: THI, Tinnitus Handicap Inventory.

$\mathrm{E}$ : Variable with asymmetric distribution (KS; $\mathrm{P}>0.200$ ).

( $r=-0.516 ; p=0.001$ ) between the operation of the sensory domain and the THI, indicating that the higher the score in the domain, the smaller the THI score.

Another significant correlation was between the total score in the WHOQOL-OLD and the THI score $(r=-0.395$; $\mathrm{p}<0.05$ ), where the total elevated scores in the WHOQOL-OLD were related to the low scores of the THI (or vice-versa). Therefore, the better the quality of life, the smaller the impact provoked by the tinnitus ( $\mathbf{- T a b l e ~} \mathbf{5}$ ).

The average scores of the WHOQOL-OLD domains were also compared to the classification in the THI. A significant difference was observed in the domain of the sensory 
Table 3 Mean and standard deviation of the THI scores according to gender and age group; and coefficient of correlation between the age and the score THI

\begin{tabular}{|l|l|l|}
\hline Variables & Score THI & $p$ \\
\hline \multicolumn{2}{|l|}{ Gender - average \pm SD (median) } & \\
\cline { 1 - 2 } Female & $30.8 \pm 26.8(22.0)$ & \\
\cline { 1 - 2 } Male & $13.8 \pm 18.9(6.0)$ & \\
\hline
\end{tabular}

Abbreviation: SD, standard deviation; THI, Tinnitus Handicap Inventory. P: Mann Whitney test.

Table 4 Measures of central tendency and variability for scores of WHOQOL-OLD domains

\begin{tabular}{|l|l|}
\hline WHOQOL-OLD & $\mathbf{n}=36$ \\
\hline Operation of the sensory & \\
\hline Average \pm SD & $14.2 \pm 3.7$ \\
\hline Minimum - Maximum & $8-20$ \\
\hline Autonomy & \\
\hline Average \pm SD & $15.1 \pm 2.9$ \\
\hline Minimum - Maximum & $8-20$ \\
\hline Past, present and future activities & \\
\hline Average \pm SD & $15.5 \pm 2.3$ \\
\hline Minimum - Maximum & $10-20$ \\
\hline Social participation & \\
\hline Average \pm SD & $15.5 \pm 2.7$ \\
\hline Minimum - Maximum & $9-20$ \\
\hline Death and dying & \\
\hline Average \pm SD & $14.9 \pm 3.8$ \\
\hline Minimum - Maximum & $5-20$ \\
\hline Intimacy & $15.6 \pm 2.6$ \\
\hline Average \pm SD & $9-20$ \\
\hline Minimum - Maximum & $11.7-17.8$ \\
\hline p (mean comparison between domains) \\
\hline Total score & \\
\hline Average \pm SD & \\
\hline Minimum - Maximum & \\
\hline
\end{tabular}

Abbreviation: SD, standard deviation; WHOQOL-OLD (World Health Organization Quality of Life -Older Adults.

$\varepsilon$ : repeated measures analysis - Post Hoc test Bonferroni p - p value.

operation ( $\mathrm{p}=0.001$ ), where the individuals with tinnitus classified as negligible and mild presented higher scores than the individuals with tinnitus impact considered moderate and severe/catastrophic. There were also differences in the total score of WHOQOL-OLD, when again the averages in the THI classification rated negligible and mild showed significantly higher averages than the ones obtained by the individuals with moderate and severe/ catastrophic THI classification (-Table 6 ).
Table 5 Correlation analysis between the scores on the WHOQOL-OLD and THI

\begin{tabular}{|l|l|l|}
\hline \multirow{2}{*}{ WHOQOL-OLD } & \multicolumn{2}{l|}{$\begin{array}{l}\text { Correlation scores } \\
\text { THI }\end{array}$} \\
\cline { 2 - 3 } & rF & $p$ value \\
\hline Operation of the sensory & -0.516 & $0.001^{* *}$ \\
\hline Autonomy & -0.123 & 0.473 \\
\hline Past, present and future activities & 0.042 & 0.809 \\
\hline Social participation & -0.118 & 0.492 \\
\hline Death and dying & -0.226 & 0.186 \\
\hline Intimacy & -0.186 & 0.277 \\
\hline Total score & -0.395 & $0.017^{*}$ \\
\hline
\end{tabular}

Abbreviation: THI, Tinnitus Handicap Inventory; WHOQOL-OLD (World Health Organization Quality of Life -Older Adults.

₹: Pearson Coefficient of correlation.

\section{Discussion}

The data obtained show that in the group of elderly evaluated, women had a predominant participation. This fact may be due to the place where the research was conducted. A study showed the massive participation of women in community groups, ${ }^{17,18}$ with an average age and age group similar to the elderly researched. ${ }^{19}$ The low education level of the participants is similar to the other national research and is a predominant characteristic in the country, and are taken into consideration when planning activities and programs for this age group. ${ }^{19}$

The THI score was similar to the study mentioned previously, where part of the sample was also composed of elderly that practice physical activities, ${ }^{20}$

but inferior to other studies that evaluated adult and elderly individuals with tinnitus. ${ }^{2,21}$ Physical activity is beneficial to the individuals evaluated. A research highlighted that the practice of physical activities is a determining factor for a lesser negative impact of the tinnitus among the elderly, possibly because it promotes the wellbeing and diminishes the discomfort sensation. ${ }^{20}$

In the analysis of THI classification, a higher number of individuals with impact considered negligible and mild corroborates other national studies, ${ }^{22}$ but differs from others ${ }^{2,23,24}$ that observed a greater number of individuals with negligible, mild and moderate discomfort. As in our study sample was composed of adult and elderly individuals, it is believed that this data can be taken into consideration, once the elderly can be more resilient, being able to adapt faster to unfavorable situations. ${ }^{25}$

When we analyzed the score obtained in the THI in our study, the elderly women presented scores superior to the men, which differs from some previous studies ${ }^{21,23,26}$ but agrees with another. ${ }^{2} \mathrm{~A}$ higher score in the evaluated women indicates that the impact provoked by the tinnitus is higher, causing a greater restriction in the social activities. Research shows that women are more careful regarding their health and that preventive care, for example, is not such an integral 
Tinnitus in Elderly Individuals: Discomfort and Impact in QoL Teixeira et al.

Table 6 Mean and standard deviation of the WHOQOL-OLD domains according to the classification THI

\begin{tabular}{|l|l|l|l|l|l|}
\hline \multirow{2}{*}{ WHOQOL-OLD } & \multicolumn{2}{|l|}{ Classification THI } & \multirow{2}{*}{ P $\mathbf{~}$} \\
\cline { 2 - 5 } & $\begin{array}{l}\text { Negligible } \\
(\boldsymbol{n}=\mathbf{1 5})\end{array}$ & $\begin{array}{l}\text { Mild } \\
(\boldsymbol{n}=\mathbf{1 1})\end{array}$ & $\begin{array}{l}\text { Moderate } \\
(\boldsymbol{n}=\mathbf{7})\end{array}$ & $\begin{array}{l}\text { Severe or catastrophic } \\
(\boldsymbol{n}=\mathbf{3})\end{array}$ & \\
\hline Operation of the sensory & $14.7 \pm 3.1 \mathrm{a}$ & $16.6 \pm 2.6 \mathrm{a}$ & $11.1 \pm 3.6 \mathrm{~b}$ & $10.0 \pm 2.0 \mathrm{~b}$ & $0.001^{*}$ \\
\hline Autonomy & $15.4 \pm 1.8$ & $15.4 \pm 3.6$ & $14.1 \pm 3.6$ & $14.0 \pm 3.6$ & 0.695 \\
\hline Past, present and future activities & $15.7 \pm 2.0$ & $15.5 \pm 2.8$ & $14.3 \pm 2.5$ & $17.0 \pm 1.0$ & 0.362 \\
\hline Social participation & $15.8 \pm 2.2$ & $15.7 \pm 3.2$ & $14.3 \pm 3.1$ & $16.0 \pm 2.6$ & 0.646 \\
\hline Death and dying & $16.1 \pm 3.7$ & $14.8 \pm 4.5$ & $13.7 \pm 3.5$ & $13.0 \pm 2.6$ & 0.450 \\
\hline Intimacy & $15.9 \pm 2.5$ & $16.2 \pm 2.1$ & $14.8 \pm 3.2$ & $13.6 \pm 3.2$ & 0.408 \\
\hline Total score & $15.6 \pm 1.2 \mathrm{a}$ & $15.7 \pm 1.8 \mathrm{a}$ & $13.7 \pm 1.3 \mathrm{~b}$ & $13.9 \pm 1.2 \mathrm{~b}$ & $0.016^{*}$ \\
\hline
\end{tabular}

Abbreviation: THI, Tinnitus Handicap Inventory; WHOQOL-OLD (World Health Organization Quality of Life -Older Adults.

p. Kruskal Wallys test - Post Hoc teste de Dunn, which means followed by the same letter do not differ significantly.

part of men's routine. ${ }^{27}$ In addition, elderly women present a self-perception regarding health that is more negative than men, ${ }^{28}$ which must be taken into account in the execution of evaluations and treatments to be prescribed for them. This may have influenced the results obtained in the research.

In the evaluation of quality of life, carried out through the WHOQOL-OLD, we observed that the score was similar in all evaluated domains, which is comparable to the results obtained in national studies with elderly individuals from community groups and who practice physical activities. ${ }^{29,30}$ The data was also similar to that obtained in studies carried out in other countries. ${ }^{31,32}$ In one of these studies, however, the score in the operation of the sensory domain was inferior to the one obtained in our study. ${ }^{32}$

The correlation analysis between the score of both instruments and the classification of the THI and the WHOQOL-OLD domains showed an association between THI and the operation of the sensory domain and the total score of the WHOQOLOLD. These results confirm the compromise of the quality of life of the elderly with tinnitus. The higher the THI score (higher discomfort provoked by the tinnitus), the lesser the score in the WHOQOL-OLD (the lesser the quality of life).

A study that used the THI and WHOQOL-bref (abbreviated instrument of evaluation of quality of life developed by WHO) showed that the quality of life of the elderly with tinnitus may be affected, especially if the elder presents insomnia. ${ }^{8}$ In another research that also used the THI and WHOQOL-bref, the results also showed a correlation with the functional and emotional domains. ${ }^{5}$ The analysis of the quality of life in the elderly with or without tinnitus

is noteworthy among the individuals with the symptom; the score in the WHOQOL-bref is significantly smaller in all domains. ${ }^{33}$

Although the studies mentioned use another version of the quality of life evaluation instrument, they helped corroborate the findings in our research, whereby tinnitus harms the quality of life of the elderly. This fact must be taken into account by the professionals at the moment of the evaluation and treatment of the individuals. Therefore, elderly, which often suffer from several health disorders that compromise their autonomy, independence, and quality of life, may present tinnitus, further decreasing their wellbeing sensation. An interdisciplinary approach, however, can promote a better study of the symptom presented, helping not only in the process of evaluation and diagnosis, but also in the establishment of the appropriate treatment for each case, contributing to an improvement in the quality of life.

\section{Conclusion}

The results obtained in our study prove that the quality of life of the elderly individuals evaluated is related to a discomfort caused by the tinnitus.

\section{References}

1 Park KH, Lee SH, Koo JW, et al. Prevalence and associated factors of tinnitus: data from the Korean National Health and Nutrition Examination Survey 2009-2011. J Epidemiol 2014;24(5):417-426

2 Karatas E, Deniz M. The comparison of acoustic and psychic parameters of subjective tinnitus. Eur Arch Otorhinolaryngol 2012;269(2):441-447

3 Nondahl DM, Cruickshanks KJ, Huang GH, et al. Generational differences in the reporting of tinnitus. Ear Hear 2012;33(5): 640-644

4 Nondahl DM, Cruickshanks KJ, Huang GH, et al. Tinnitus and its risk factors in the Beaver Dam offspring study. Int J Audiol 2011; 50(5):313-320

5 Zeman F, Koller M, Langguth B, Landgrebe M; Tinnitus Research Initiative database study group. Which tinnitus-related aspects are relevant for quality of life and depression: results from a large international multicentre sample. Health Qual Life Outcomes 2014;12:7

6 Teixeira AR, Rosito LPS, Seimetz BM, Dall'Igna C, Costa SS. Chronic tinnitus: pith, loudness, and discomfort in adults and elderly patients. In: Atkinson $\mathrm{CH}$. Handbook of hearing disorders research. Nova BiomedicalNew York2015. p. 93-103.

7 Fujii K, Nagata C, Nakamura K, et al. Prevalence of tinnitus in community-dwelling Japanese adults. J Epidemiol 2011;21(4): 299-304

8 Lasisi AO, Gureje O. Prevalence of insomnia and impact on quality of life among community elderly subjects with tinnitus. Ann Otol Rhinol Laryngol 2011;120(4):226-230 
9 Turner O, Windfuhr K, Kapur N. Suicide in deaf populations: a literature review. Ann Gen Psychiatry 2007;6:26

10 Hoekstra CE, Wesdorp FM, van Zanten GA. Socio-demographic, health, and tinnitus related variables affecting tinnitus severity. Ear Hear 2014;35(5):544-554

11 Mucci S, Geocze L, Abranches DC, Antúnez AEA, Penido NdeO. [Systematic review of evidence on the association between personality and tinnitus]. Braz J Otorhinolaryngol 2014;80(5): 441-447

12 Baldo P, Doree C, Molin P, McFerran D, Cecco S. Antidepressants for patients with tinnitus. Cochrane Database Syst Rev 2012;9: CD003853

13 Newman CW, Jacobson GP, Spitzer JB. Development of the Tinnitus Handicap Inventory. Arch Otolaryngol Head Neck Surg 1996; 122(2):143-148

14 Schmidt LP, Teixeira VN, Dall'Igna C, Dallagnol D, Smith MM. Adaptação para a língua portuguesa do questionário Tinnitus Handicap Inventory: validade e reprodutibilidade. Rev Bras Otorrinolaringol (Engl Ed) 1996;72:808-810

15 WHOQOL GROUP. The world health organization quality of life assessment (WHOQOL): position paper from the World Health Organization. Soc Sci Med 1995;41(10):1403-1409

16 Fleck MP, Chachamovich E, Trentini CM. WHOQOL-OLD Project: method and focus group results in Brazil. Rev Saude Publica 2003; 37(6):793-799

17 Benedetti TRB, Mazo GZ, Borges LJ. Health status and physical activity levels among the elderly who are participants and nonparticipants in social welfare groups in Florianópolis. Cien Saude Colet 2012;17(8):2087-2093

18 Gonçalves AK, Griebler EM, Possamai VD, Teixeira AR. Qualidade de vida e sintomas depressivos em idosos de três faixas etárias praticantes de atividade física. Rev Kairós. 2014;17(3):79-94

19 Pilger C, Menon MH, Mathias TAF. Características sociodemográficas e de saúde de idosos: contribuições para os serviços de saúde. Rev Latino-Am de Enfermagem 2011;19:1230-1238

20 de Arizola HGA, Teixeira AR. Impacto do zumbido em idosos praticantes e não praticantes de exercício físico. Conscientiae Saúde $2015 ; 14(1): 80-88$
21 Udupi VA, Uppunda AK, Mohan KM, Alex J, Mahendra MH. The relationship of perceived severity of tinnitus with depression, anxiety, hearing status, age and gender in individuals with tinnitus. Int Tinnitus J 2013;18(1):29-34

22 Pinto PCL, Sanchez TC, Tomita S. Avaliação da relação entre severidade do zumbido e perda auditiva, sexo e idade do paciente. Braz J Otorhinolaryngol. 2010;76(1):18-24

23 Fioretti AB, Fusetti M, Eibenstein A. Association between sleep disorders, hyperacusis and tinnitus: evaluation with tinnitus questionnaires. Noise Health 2013;15(63):91-95

24 Gois RO, Gois BO, Pereira MCCS, Taguchi CK. Estado mental e impacto do zumbido em idosos. Rev CEFAC 2014;16:798-809

25 Ferreira CL, Santos LMO, Maia EMC. Resilience among the elderly cared for by the primary healthcare network in a city of northeast Brazil. Rev Esc Enferm USP 2012;46(2):328-334

26 Alsanosi AA. Impact of tinnitus on the quality of life among Saudi patients. Saudi Med J 2011;32(12):1274-1278

27 Alves RF, Silva RP, Ernesto MV, Lima AGB, Souza FM. Gênero e saúde: o cuidar do homem em debate. Psicol Teor Prat 2011; 13:152-166

28 Silva RJS, Smith-Menezes A, Tribess S, Rómo-Perez V, Virtuoso JS Jr. Prevalence and factors associated with negative health perception by the Brazilian elderly. Rev Bras Epidemiol 2012;15(1):49-62

29 Serbim AK, Figueiredo AEPL. Qualidade de vida de idosos de um grupo de convivência. Sci Med 2011;21:166-172

30 de Souza Santos CA, Dantas EEM, Moreira MHR. Correlation of physical aptitude; functional capacity, corporal balance and quality of life (QoL) among elderly women submitted to a postmenopausal physical activities program. Arch Gerontol Geriatr 2011;53(3):344-349

31 Top M, Eris H, Kabalcioglu F. Quality of life (QoL) and attitudes toward aging in older adults in Sanliurfa, Turkey. Res Aging 2012; 35:533-562

32 Bilgili N, Arpacı F. Quality of life of older adults in Turkey. Arch Gerontol Geriatr 2014;59(2):415-421

33 Negrila-Mezei A, Enache R, Sarafoleanu C. Tinnitus in elderly population: clinic correlations and impact upon QoL. J Med Life $2011 ; 4(4): 412-416$ 